\title{
The Winner Curse and Social Inefficiency: Double Whammy of R\&D Tournament
}

\author{
Arijit Mukherjee', Leonard F.S.Wang²
}

\begin{abstract}
In a R\&D tournament setting with free entry and knowledge spillover, we show that the society would suffer from excessive entry and the patent holder would endure lower profits than non-patent holders because it bears the cost of commercializing and further technology development, while the other firms are beneficiaries of the spillover effects. This result is instructive to R\&D and competition policy.
\end{abstract}

Keywords: R\&D tournament; excessive entry; insufficient entry.

\footnotetext{
I University of Nottingham and The Leverhulme Centre for Research in Globalisation and Economic Policy, UK, and CESifo, Germany Room B40 Sir Clive Granger Building, University Park, Nottingham NG7 2RD, UK. Phone:0I I 5-95-I 4733, Fax:0 I I 5-95-I4I 59, E-mail: arijit.mukherjee@nottingham.ac.uk

2 Department of Applied Economics, National University of Kaohsiung, No. 700, Kaohsiung University Road, Nan-Tzu District 8II, Kaohsiung, Taiwan, R.O.C. Phone:886-7-5919322, Fax:886-7-5919320, E-mail: Ifswang@nuk.edu.tw. Correspondence author: Leonard F. S. Wang, Department of Applied Economics, National University of Kaohsiung, No. 700, Kaohsiung University Road, Nan-Tzu District 8I I, Kaohsiung, Taiwan, R.O.C.Tel:886-7-5919322, Fax:886-7-5919320, E-mail address: Ifswang@nuk.edu.tw
} 


\section{Introduction}

In an influential work, Mankiw and Whinston (1986) show that entry in oligopolistic markets is socially excessive in the presence of scale economies, providing the rationale for anti-competitive entry regulation in oligopolistic markets. This result, often called "excess-entry theorem", has created significant interest in analyzing the welfare effects of entry in oligopolistic markets'. Although it is generally believed for long time that entry is socially excessive in oligopolistic industries with scale economies, recent contributions show concern to this belief by considering spatial competition (Matsumura and Okamura 2006), market powers of the intermediate goods producers and the final goods producers (Ghosh and Morita, 2007a and b), technology licensing (Mukherjee and Mukherjee 2008), external economies of scale (Mukherjee, 2010) and market leadership (Mukherjee, 20llb).

The "excessive-entry" literature has been extended is several directions in recent years, yet an important aspect, viz., endogenous technology choice of the firms, did not get much attention. The previous works in this literature consider that the technology choice of the firms are not affected by the market structure, while it is well-known that market structure plays an important role in determining the technologies of the firms (Schumpeter, 1943 and Arrow, 1962) ${ }^{2}$. De Bondt (1997) provides a critical survey of wide class settings including stochastic racing model, dynamic and static commitment, and strategic investment model that look at spillovers in innovative activity.

In the literature on non-Tournaments R\&D, PoyagoTheotoky (1999) explores the information sharing behavior among firms with endogenous spillover effects.
Based on Poyago-Theotoky (1999), Tesoriere (2006) also endogenizes spillover effects in non-Tournament R\&D model and further considers the possibility of asymmetric spillover effect to elaborate the optimality in a research joint venture. Nisvan and Piccinin (2010) analyze the effects of cooperative R\&D arrangements in a model which allows for free entry into both the product market and the stochastic R\&D process with spillovers. They show that sharing of research outcomes is a necessary condition for the profitability of cooperative R\&D arrangements with free entry.

In this paper, we consider a situation where the patent system makes the R\&D process as a tournament (Roy Chowdhury, 2005, Zhou, 2006, Mukherjee, 2006 and Mukherjee, 2008), where only one successful firm in R\&D is granted patent for the new innovated technology $y^{3}$ We show that if there is R\&D tournament, entry is socially excessive irrespective of small and large knowledge spillovers or non-infringing imitations, which help the non-patent holders to get the advantage of the technology used by the patent holder ${ }^{4}$.

Due to common intellectual property protection schemes around the world, R\&D competition is often Tournamentliked. It is to say that there is one and only one can ultimately be entitled the privilege of owning the patent. Therefore, IPR policies and competition policies towards the industries without legal entry barriers should be carefully designed to prevent this double-whammy effect.

The remainder of the paper is structures as follows. Section 2 describes the model and shows the result. Section 3 concludes.

\footnotetext{
' See,Von Weizsäcker (1980), Suzumura and Kiyono (1987), Okuno-Fujiwara and Suzumura (1993), Fudenberg and Tirole (2000) for other works on excessive entry in the presence of scale economies. Klemperer (1988), Lahiri and Ono (1988) and Ghosh and Saha (2007) suggest that excessive entry can occur without scale economies but in the presence of marginal cost difference.

${ }^{2}$ Klemperer (1988), Lahiri and Ono (1988) and Ghosh and Saha (2007) show the welfare effects of entry in the presence of exogenously given cost asymmetry but with no scale economies, yet the extent of cost asymmetry does not depend on the market structure. Recently, Mukherjee (20 I la) endogenize cost asymmetry by considering one innovating and all other non-innovating firms, thus ignoring strategic investment in innovation. In contrast to these papers, we consider strategic R\&D investments of the firms in the present paper. ${ }^{3}$ See Zhou ( 2006). It examines first the relation between the R\&D process that represented by the form of uncertainty and the market structure as well as contestants' R\&D spending. The research than illustrates the relation between the magnitude of the spillover effect and the contestants' R\&D spending.

${ }^{4}$ Haruna and Goel (20II) consider social efficiency of entry in the presence of R\&D competition between the firms, and show that excessive entry occurs as long as research spillovers are relatively small, but that is not necessarily the case with large spillovers.
}

ISSN: 07I8-2724. (http://www.jotmi.org) 


\section{The model and the results}

Assume that there is large number of firms who can enter the market by incurring an entry cost $E$. Each firm can produce a homogeneous product with a marginal cost $d$. We assume that, ex-post entry, each firm invests in research to invent a new technology, which reduces its marginal cost of production to $c$. For simplicity, we ignore the cost of research, since it will not add new insights to our analysis. Success in research is certain. However, we assume that only one innovator will get the patent for the new invented technology. The patent owner will invest in developing or commercializing the new technology. If the patent owner invests $x$ amount in developing the technology, it can reduce the marginal cost relating to the new technology to $(c-x)$. We assume that the cost of developing the new technology is $X^{2}$. We also assume that the non-patent owners can get the benefit of the patent holder's technology through knowledge spillover or noninfringing imitation, which reduces the marginal cost of a non-patent owner to $(c-g x)$, where $g \in[0,1]$ is the degree of knowledge spillover as specified in D'aspremont and Jacquemin $(1988)^{5}$. Hence, $g$ may show the effectiveness of the patent system.

We consider the following game. At stage I, the firms decide whether to enter the industry. At stage 2, the firms, which have entered the market, conducts research and invents the new technology. At stage 3, the patent is granted to one innovator. At stage 4, the patent owner invests in developing the new invented technology. At stage 5 , the firms, which have entered the market, choose their outputs simultaneously and the profits are realized. We will consider $d=c$ in the following analysis, in order to abstract our analysis from the initial cost asymmetries of the patent owner and the non-patent owners, thus showing the implications of R\&D tournament only ${ }^{6}$. Hence, we can consider our situation as follows. The existing technologies of the firms are standardized and there are no scopes for improving them. The new invented technology is similar to that of the existing technologies without development, yet there is scope for improving the new technology.
We assume that the inverse market demand function is

$\mathrm{P}=\mathrm{a}-\mathrm{q}$

where $P$ is price and $q$ is the total output.

If $\mathrm{n}$ firms enter the market, the ith firm's profit,

$i=1,2, \ldots, n i=1,2, \ldots, n$, is

$\pi_{i}=\frac{1}{n}\left(\frac{a-n\left(c-x_{i}\right)+(n-1)\left(c-g x_{1}\right)}{n+1}-x_{i}^{2}\right)^{2}+$

$\left(1-\frac{1}{n}\right)\left(\frac{a-2\left(c-g x_{-i}\right)+\left(c-x_{-i}\right)}{n+1}\right)^{2}$

Let us explain expression (2), which shows the ith firm's net expected profit from innovation. If $n$ firms enter the market and innovate the technology, the ith firm's probability of becoming the patent owner is $\frac{1}{n}$. If the ith firm is the patent owner and invests $X_{i}$ in developing the technology, its marginal cost of production is and the marginal cost of each of the other $(n-1)$ firms is $\left(c-g x_{i}\right)$. Hence, the ith firm's expected profit from patent approval is $\frac{1}{n}\left(\frac{a-n\left(c-x_{i}\right)+(n-1)\left(c-g x_{i}\right)}{n+1}-x_{i}^{2}\right)^{2}$.

The probability that the ith firm is not the patent owner is $\left(1-\frac{1}{n}\right)$. If the firms other than the firm $i$ owns the patent and invests $X_{-i}$, the marginal cost of the firm becoming the patent owner is $\left(c-x_{-i}\right)$ and each of the other firm's (including firm $i)$ is $\left(c-g x_{-i}\right)$. Hence, the expected profit of the $i$ th firm from not owning the patent is

$\left(1-\frac{1}{n}\right)\left(\frac{a-2\left(c-g x_{-i}\right)+\left(c-x_{-i}\right)}{n+1}\right)^{2}$.

${ }^{5}$ As in De Bondt (1997), spillovers will here be equivalent to knowledge spillovers: involuntary leakage or voluntary exchange of useful technology information.

${ }^{6}$ The effects of the initial cost asymmetries between an innovator and the non-innovators have been discussed in Mukherjee (20I la). 
Firm $i$ maximizes (I) to determine its investment in developing the technology. Due to the symmetry of the firms, we get the equilibrium investment by each firm, which has entered the industry, in developing the invented technology as

$$
x_{i}^{*}=x_{-i}^{*}=x^{*}=\frac{(a-c)[n-g(n-1)]}{[1+g(n-1)][1+2 n-g(n-1)]}
$$

If $n$ firms enter the industry, the net profit of each firm is

$$
\pi_{i}^{*}-E=\frac{(a-c)^{2}\left[\begin{array}{l}
3 n+g(n-1)(-2+6 n \\
\left.+g\left(4+g(g-2)-7 n-2 g n(g-3)+n^{2}(g-2)^{2}\right)\right)
\end{array}\right]}{n[1+g(n-1)]^{2}[1+2 n-g(n-1)]^{2}}-E
$$

The equilibrium number of firms, which enters the industry, is given by $\pi_{\mathrm{i}}^{*}=\mathrm{E}$. Given the complicated expression in (3), we focus on two extreme situations: (i) where the patent system is completely effective, i.e., $g=0$, and (ii) where the patent system is not effective at all, i.e., $g=1$.

First, consider the case where $g=0$. In this situation, the equilibrium investment in developing the new technology is $x^{*}(g=0)=\frac{(a-c) n}{1+2 n}$ and the equilibrium number of firms entering the industry is given by $\pi_{\mathrm{i}}^{*}(g=0)=\mathrm{E}$ or $\frac{3(a-c)^{2}}{(1+2 n)^{2}}=E$.

Next, consider the case where $g=1$. In this situation, the equilibrium investment in developing the new technology is $x^{*}(g=1)=\frac{a-c}{n(n+2)}$ and the equilibrium number of firms entering the industry is given by $\pi_{\mathrm{i}}^{*}(g=1)=E$ or $\frac{(a-c)^{2}\left(n+2 n^{2}+n^{3}-1\right)}{n^{3}(n+2)^{2}}=E$

\section{I. Welfare maximizing number of firms}

Now consider the welfare maximizing number of the firms entering the industry. The expected welfare of the economy is given by the sum of expected consumer surplus and the net expected profits of the all firms entering the industry. Given the symmetry of the firms, the identity of the firm getting the patent protection is not important for welfare. Since at least one firm owns the patent, if $n$ firms enter the industry, and therefore, each firm invests in developing the new technology according to (3), welfare is

$\mathrm{W}=\mathrm{n}\left(\pi_{\mathrm{i}}^{*}-\mathrm{E}\right)+\mathrm{CS}$

where

$C S=\frac{1}{2}\left(\frac{a-n\left(c-x^{*}\right)+(n-1)\left(c-g x^{*}\right)+(n-1)\left(a-2\left(c-g x^{*}\right)+\left(c-x^{*}\right)\right)}{n+1}\right)^{2}$

shows the consumer surplus. Using (3), (4) and (5), we get the welfare as

$W=\frac{(a-c)^{2}\left[\begin{array}{l}g^{4}(1+n)(n-1)^{3}+2 n(3+2 n)-2 g^{3}(n-1)^{2}\left(n+2 n^{2}-1\right) \\ +4 g\left(1-3 n+2 n^{3}\right)+g^{2}(n-1)(7+n(-5+4 n(n-1)))\end{array}\right]}{2[1+g(n-1)]^{2}[1+2 n-g(n-1)]^{2}}-n E$

Now consider the two extreme cases of $g=0$ and $g=1$. If $g=0$, welfare is

$\mathrm{W}(\mathrm{g}=0)=\frac{(\mathrm{a}-\mathrm{c})^{2} \mathrm{n}(3+2 \mathrm{n})}{(1+2 \mathrm{n})^{2}}-\mathrm{nE}$ and the welfare maximizing number of firms is given by $\frac{(a-c)^{2}(3-2 n)}{(1+2 n)^{3}}=E$

Next, consider the case of $g=1$. In this situation, welfare is

$W(g=1)=\frac{(a-c)^{2}\left(-2+2 n+5 n^{2}+4 n^{3}+n^{4}\right)}{2 n^{2}(2+n)^{2}}-n E$

and the welfare maximizing number of firms is given by

$\frac{(a-c)^{2}(1+n)[4-n(2+n)]}{n^{3}(2+n)^{3}}=E$

\subsection{Excess entry}

Now we consider whether entry is excessive or insufficient from the social point of view.

First, consider the case of $g=0$. Subtracting the left hand side (LHS) of the equation determining the welfare maximizing number of firms from LHS of the equation for the free entry equilibrium number of firms, we get that $\left[\frac{3(a-c)^{2}}{(1+2 n)^{2}}-\frac{(a-c)^{2}(3-2 n)}{(1+2 n)^{3}}\right]=\frac{8 n(a-c)^{2}}{(1+2 n)^{3}}>0$, implying that entry is socially excessive. 
Next, consider the case of $g=1$. Subtracting LHS of the equation determining the welfare maximizing number of firms from LHS of the equation for the free entry equilibrium number of firms, we get that

$$
\begin{aligned}
& {\left[\frac{(a-c)^{2}\left(n+2 n^{2}+n^{3}-1\right)}{n^{3}(n+2)^{2}}-\frac{(a-c)^{2}(1+n)[4-n(2+n)]}{n^{3}(2+n)^{3}}\right]} \\
& =\frac{(a-c)^{2}\left(-6-n+8 n^{2}+5 n^{3}+n^{4}\right)}{n^{3}(2+n)^{3}}>0
\end{aligned}
$$

implying that entry is socially excessive.

Thus, we show that entry is socially excessive under both low and high knowledge spillovers in the presence of R\&D tournament. The economic reason for this difference is as follows. In contrast to R\&D competition, where all the successful firms use the invented technology, only one successful firm gets the patent for the new technology under R\&D tournament. Therefore, even the possibility of becoming the sole patent-holder may create significant interest for entering the industry but paradoxically the patent holder would endure lower profits than non-patent holders because it bears the cost of commercializing and further technology development, while the other firms are beneficiaries of the spillover effect. The society would suffer from the problem of excessive entry accordingly.

\section{Conclusion}

Mankiw and Whinston (1986) show that entry in oligopolistic markets is socially excessive in the presence of scale economies, providing the rationale for anticompetitive entry regulation in oligopolistic markets. Considering R\&D tournament with free entry and knowledge spillover, we show that the society would suffer from the problem of excessive entry and the patent holder would endure lower profits than non-patent holders because it bears the cost of commercializing and further technology development, while the other firms are beneficiaries of the spillover effects.

Due to common intellectual property protection schemes around the world, R\&D competition is often Tournamentliked. Therefore, IPR policies and competition policies towards the industries without legal entry barriers should be carefully designed to prevent this double-whammy effect.

\section{References}

ARROW, K. (1962) Economic welfare and the allocation of resources for invention. In: . Nelson, R. (ed.), The Rate and Direction of Inventive Activity. Princeton: Princeton University Press.

D'ASPREMONT, C., Jacquemin, A. (1988) Cooperative and noncooperative R\&D in duopoly with spillovers. American Economic Review, 78, II33-II37.

DE BONDT, R. (1997) Spillovers and innovative activities. International Journal of Industrial Organization, 15, I-28.

FUDENBERG, D., Tirole, J. (2000) Pricing a network good to deter entry. Journal of Industrial Economics, 48, 373-390.

GHOSH, A., Morita, H. (2007a) Free entry and social efficiency under vertical oligopoly. Rand Journal of Economics, 38, 539-552.

GHOSH, A., Morita, H. (2007b) Social desirability of free entry: a bilateral oligopoly analysis. International Journal of Industrial Organization, 25, 925-934.

GHOSH, A., Saha, S. (2007) Excess entry in the absence of scale economies. Economic Theory, 30, 575-586.

HARUNA, S., Goel, R. K. (20II) R\&D, free entry, and social efficiency. Economics of Innovation and New Technology, 20, 89-I0I.

KLEMPERER, P. (1988) Welfare effects of entry into markets with switching costs. Journal of Industrial Economics, 37, 159-165.

LAHIRI, S., Ono, Y. (1988) Helping minor firms reduces welfare. Economic Journal, 98, 1199-1202.

MANKIW, N.G., Whinston, M. D. (1986) Free entry and social inefficiency. Rand Journal of Economics, 17, 48-58.

MATSUMURA, T., Okamura, M. (2006) A note on the excess entry theorem in spatial markets. International Journal of Industrial Organization, 24, 107I-1076.

MUKHERJEE, A. (2006) Patents and R\&D with imitation and licensing. Economics Letters, 93, 196-20I. 
MUKHERJEE, A. (2008) Patent protection and R\&D with endogenous market structure. Journal of Industrial Economics, 56, 862 (full version is available at www.essex. ac.uk/jindec/).

MUKHERJEE, A. (20I0). External economies of scale and insufficient entry. Journal of Industry, Competition and Trade, 10, 365-37।.

MUKHERJEE, A. (20lla). Endogenous cost asymmetry and insufficient entry in the absence of scale economies. Journal of Economics (Forthcoming).

MUKHERJEE, A. (20llb) Social efficiency of entry with market leaders. Journal of Economics \& Management Strategy (Forthcoming).

MUKHERJEE, A., Mukherjee, S. (2008) Excess-entry theorem: the implications of licensing. The Manchester School, 76, 675-689.

NISVAN, E., Piccinin, D. (2010) Cooperative R\&D under uncertainty with free entry. International Journal of Industrial Organization, 28, 74-85.

OKUNO-FUJIWARA, M., Suzumura, K. (1993) Symmetric Cournot oligopoly and economic welfare: a synthesis. Economic Theory, 3, 43-59.

POYAGO-THEOTOKY, J. (1999) A note on endogenous spillovers in a non-tournament R\&D duopoly. Review of Industrial Organization, 15, 253-262.

ROY CHOWDHURY, P. (2005) Patents and R\&D: the tournament effect. Economics Letters, 89, 120-26.

SCHUMPETER, J. (1943) Capitalism, Socialism and Democracy. London: Allan and Unwin.

SUZUMURA, K. (1995) Competition, Commitment and Welfare. Oxford: Clarendon Press.

SUZUMURA, K., Kiyono, K. (1987) Entry barriers and economic welfare. Review of Economic Studies, 54, 157-167.

TESORIERE, A. (2008) A further note on endogenous spillovers in a non-tournament R\&D duopoly. Review of Industrial Organization, 33, 177-184.
VON WEIZSÄCKER, C.C. (1980) A welfare analysis of barriers to entry. Bell Journal of Economics, II, 399-420.

ZHOU , H. (2006) R\&D tournaments with spillovers. Atlantic Economic Journal, 34, 327-339. 
J. Technol. Manag. Innov. 20II,Volume 6, Issue 4 